\title{
Modeling of Stochastic Volatility to Validate IDR Anchor Currency ${ }^{*}$
}

\author{
Didit B. Nugrobo, ${ }^{1,3}$ Tundjung Mahatma, ${ }^{1}$ and Yulius Pratomo ${ }^{2,3}$ \\ ${ }^{1}$ Department of Mathematics in Faculty of Science and Matemathics, \\ Satya Wacana Christian University, Salatiga, Indonesia \\ ${ }^{2}$ Department of Economics in Faculty Economics and Business, \\ Satya Wacana Christian University, Salatiga, Indonesia \\ ${ }^{3}$ Member of Study Center for Multidisciplinary Applied Research and Technology (SeMARTy)
}

\begin{abstract}
This study aims to assess the performance of stochastic volatility models for their estimation of foreign exchange rate returns' volatility using daily data from Bank Indonesia (BI). The model is then applied to validate the anchor currency of Indonesian rupiah (IDR). Two stylized facts are incorporated into the models: A correlation between the previous returns and their conditional variance, and return errors following four different error distributions namely Normal, Student- $t$, non-central Student- $t$, and generalized hyperbolic skew Student- $t$. The analysis is based on the application of daily returns data from nine foreign currency selling rates to IDR from 2010 to 2015, including the AUD, CHF, CNY, EUR, GBP, JPY, MYR, SGD, and USD. The main results are: (1) Mixed evidence of positive and negative relationships between the return and its variance were found, especially significant correlations being found for the IDR/AUD, IDR/CHF, IDR/JPY, IDR/SGD, and IDR/USD returns series; (2) the model with the generalized hyperbolic skew Student's $t$-distribution specification for the returns error provides the best performance; and (3) anchoring the IDR to established hard currencies is more appropriate than anchoring it to other currencies.
\end{abstract}

Keywords: anchor currency; asymmetric; generalized Student- $t$; stochastic volatility

JEL classification: C32, G12, G13

* The research leading to these results has received funding from the Ministry of Research, Technology and Higher Education of the Republic of Indonesia via Competitive Grant No. 001/K6/KM/SP2H/ RISTEKTERAPAN/2016 and Satya Wacana Christian University.

* Corresponding author's e-mail: didit.budinugroho@staff.uksw.edu 


\section{Introduction}

The volatility of financial assets' returns, such as stock indexes and exchange rates, is often perceived as a measure of the security risk based on the fluctuations of those returns. Also, it is believed that volatility could also be used to examine government interventions in the financial markets (Goyal 2017). In addition, with regard to volatility, for some people, is important to look at the existence of exchange rate overshooting (an effect caused by people overreacting to monetary policy). This volatility is defined by Abdalla and Winker (2012) as a statistical measure of the dispersion of returns for a given security or market index which can be measured by the square root of return's variance. Numerous theoretical and empirical studies have shown that higher exchange rate volatility leads to higher costs for risk averse traders.

Because the volatility is considered to be an important concept in the field of economics and financial applications, various models have been developed to measure volatility, including the seminal paper by Engle (1982). Engle (1982) studied the Autoregressive Conditional Heteroscedastic (ARCH) model and Bollerslev (1986) extended the work to the Generalized ARCH (GARCH) model. Their models define the time-varying squared-volatility as a deterministic function of lagged conditional squared-volatility and past squarederror. A model which is more flexible and allows a more natural economic interpretation than GARCH model is the Stochastic Volatility (SV) model introduced by Taylor (1982). The SV model defines volatility as a logarithmic first order autoregressive process.

Several studies find that the returns series usually exhibit a leptokurtic distribution (i.e. heavy-tails with high kurtosis distributions) and the returns volatility exhibits an asymmet- ric effect (i.e. correlation between the return errors and volatility errors). Recently, the conditional distribution of the returns has been extended to the asymmetric distributions such as non-central Student- $t$, symmetric or skewed Student- $t$, Generalized Error Distribution (GED), and mixtures of normals. Nugroho and Morimoto $(2014,2016)$ provided statistical evidence supporting the incorporation of skewed Student- $t$ into the stock data returns error. Meanwhile, two documented theories attempting to explain the asymmetric effect are Black (1976) and Low (2004). In the context of the SV models, the asymmetric effect was introduced by Taylor (1994) and Harvey and Shephard (1996) by incorporating the fact that volatility responds asymmetrically to past returns for differents signs, meaning that volatility is higher after negative shocks than after positive shocks of a similar size.

Over the last decade, there is competition between several currencies, including the US dollar and Euro, where they attempt to be the prime anchor currency (Eichengreen 2005). At the same time, United Nations (UN) has a desire to replace the US dollar as the global currency (Conway 2009). This fact has raised a question for many countries as to whether they should replace the US dollar as an anchor currency in the future or not. Also, this might be seen as the time for any other emerging reserve currencies, for instance the Australian dollar and Yuan to be the next leading currencies. However, it is believed that, for the foreseeable future, the US dollar will still be the main anchor currency (Eichengreen 2005). This debatable situation has increased interest in research into this.

Accordingly, the purpose of this study is to examine the ability of the univariate SV models to capture the stylized facts mentioned earlier in the Indonesian foreign market by assuming that the return errors follow a gen- 
eralized Student- $t$ distribution, the volatility errors follow a normal distribution, and there is a correlation between the errors in the returns and volatility. The paper contributes to this literature in three aspects. First, currency exchange data sets from Indonesia, not previously considered in the literature, are used, especially in the SV context. On the empirical level, several applications have been found for developing the Indonesian market through the GARCH models. For example, Sumiyana (2007) studied the behavior of the daily returns' volatility on the Indonesian stock exchange market by using size, trading volume, bid-ask spreads, and an up-down market. Recently, Saadah and Panjaitan (2016) indentified the volatility of IPO share prices on the Indonesian stock exchange market during 20002013 through the GARCH model. Moreover, Triady et al. (2016) investigated the presence of a leverage effect by the Indonesian stock market using the EGARCH model. On the Indonesian foreign exchange market, Mukhlis (2011), Saputri et al. (2016), and Salim et al. (2016) investigated the behavior of exchange rate volatilities for the US dollar (USD), Japanese yen (JPY), and Euro (EUR) data sets using the GARCH-type models. Recently, Nugroho, Susanto and Pratama (2017) and Nugroho and Susanto (2017) investigated the daily exchange rates for the Indonesian rupiah (IDR) on return volatility using APARCH(1,1)type models. Second, our study takes two nonnested generalized Student- $t$ distributions to the return errors' distribution and an asymmetric effect between volatility risk and asset returns in the SV model. Comparisons of the performance of the SV models have not yet been made for the Indonesian foreign currency exchange rate return series. Third, this study evaluates whether anchoring to hard currencies is appropriate or not on the basis of volatility persistence. This is important because there are several emerging hard currencies, including the AUD and CNY.

Because the likelihood function of the SV model is difficult to directly evaluate, many procedures have been proposed. In this study, authors apply a procedure from the Riemann Manifold Hamiltonian Monte Carlo (RMHMC) method within the Markov Chain Monte Carlo (MCMC), based on the paper by Nugroho and Morimoto (2015). The RMHMC method is a tool which can efficiently estimate the entire log volatility at once.

This study is organized as follows: The methods section describes the scope of study and variables, the data which is used in this study, descriptive statistics of the returns, the proposed models and their estimation by using MCMC, and the criteria for the model's selection. The next section discusses the main results of this study. The final section presents the conclusions and future works.

\section{Methods}

To meet the objectives, authors set the scope of this study, define the variables, and describe the non-normality, no autocorrelation, and stationarity of the return series, which are common assumptions in many time series techniques. The data is then adapted to the proposed model in order to achieve the objectives.

\section{Scope of the Study and the Variables}

The main objective of this study is to characterize a univariate SV model by its ability to capture important stylized facts (such as the persistence of volatility, asymmetric effects, heavy tails, and skewness) and to validate the appropriateness of the anchor currency for IDR exchange rates. The study uses daily fi- 
nancial time series data covering the period from January 2010 to December 2015 -following the global financial crisis of 2008-2009excluding weekends and holidays. Authors chose to pick 6 years of daily prices so that authors have at least 1,000 trade days which can describe clear and reliable time series as suggested by the relevant literature [see, for example, Harvey and Shephard (1996), Poon (2005), Abdalla and Winker (2012)]. Considering that the calculation and result would be more reliable and accurate, the model examined only one variable, the IDR exchange rate. In terms of the volume of currency trading, Indonesia experiences large foreign currency transactions. Sadikin, the Director of PT Bank

Figure 1. Time Series Plots for Daily Exchange Rates of the Nine Currencies
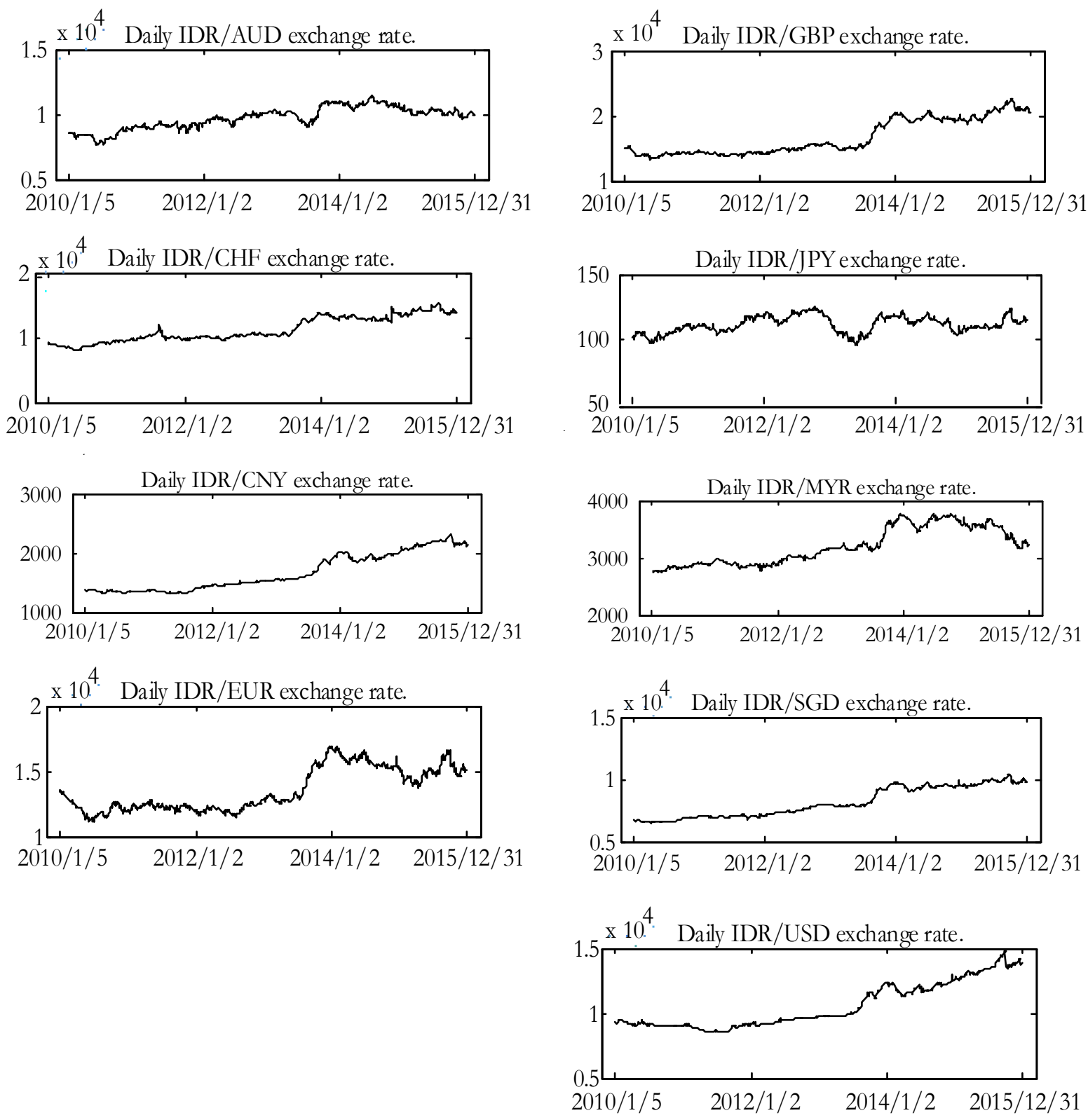
Figure 2. Time Series Plots for Percentage Daily Returns of the Nine Currencies
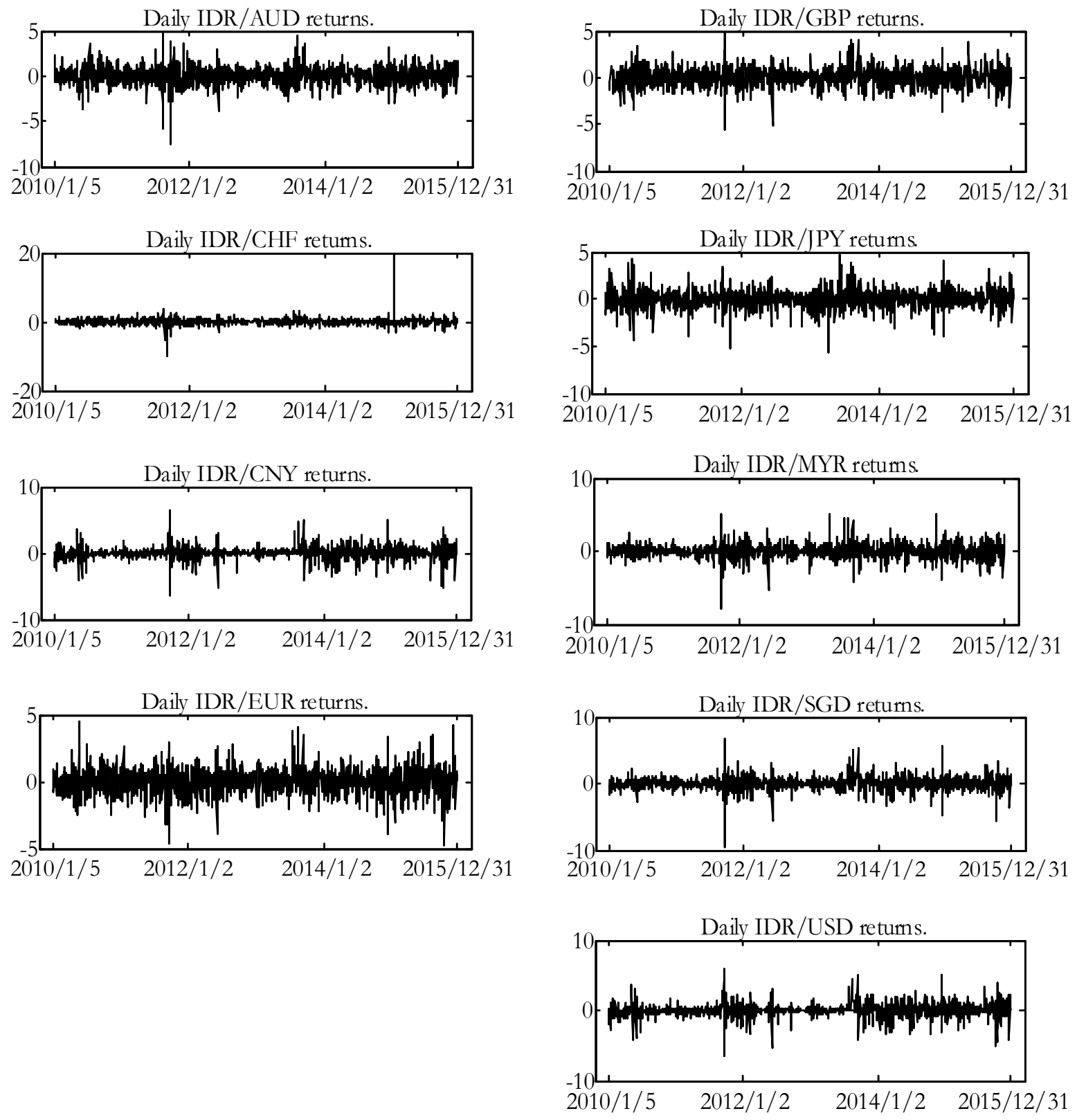

Mandiri, stated that the foreign exchange market for Indonesia's transactions equals USD 2 billion to 3 billion per day (Kompas 2015).

The model's approach and the variable are consistent with the literature's approach to modeling a currency exchange rate. As stated earlier, a thorough search of the rel-

evant literature did not find any extensive work on IDR exchange rates in terms of the considered models as well as the method involved in the analyses. A similar study has only been undertaken by Tsiotas (2012) using a different SKT distribution. 


\section{Definition of the Variable and Data Used for the Analysis}

In finance, a foreign exchange rate between two currencies is how much one unit of a currency can be exchanged for another currency. In particular, the selling (buying) rate is the rate at which money dealers will sell (buy) foreign currency. The dealers usually quote a currency pair in terms of buying/selling a currency. Here, the quotation $X / Y$ means that the dealer will receive $X$ for selling one $Y$ to the client, or in other words, the client must pay $X$ to the dealer to buy one $Y$.

Many currencies are traded on the Indonesia foreign exchange market. In particular, this study uses daily data of nine foreign currencies to the IDR, including the Australian dollar (AUD), Swiss franc (CHF), Chinese yuan (CNY), EUR, British pound (GBP), Japanese yen (JPY), Malaysian ringgit (MYR), Singapore dollar (SGD), and the USD. Notice that the EUR, CHF, GBP, JPY, and USD are major currencies in the world's economy in 2010 (Salvatore 2013). The AUD, MYR and SGD currencies are included in the top five IDR exchange rates as stated by XE (2017). Moreover, the MYR currency has the highest bid-ask spreads (the SGD having moderate spreads) against the USD, EUR, JPY, higher than other East Asian currencies (Moon 2007; Ogawa and Shimizu 2009), while the AUD could be used as an investment currency in a carry trade regime (Kim 2015). The CNY is a new currency that has been added to the existing IMF Special Drawing Rights (IMF 2016).

The data sets were downloaded from BI's internet website (http://www.bi.go.id). Authors use the percentage of mean-corrected and variance-scaled returns defined by

$$
R_{t}=100 \times \frac{Y_{t}}{s\left(Y_{t}\right)}
$$

$$
\text { with } Y_{t}=\ln \left(\frac{P_{t}}{P_{t-1}}\right)-\frac{1}{T} \sum_{t=1}^{T} \ln \left(\frac{P_{t}}{P_{t-1}}\right)
$$

where $P_{t}$ is the selling rate of foreign currency at time $t$ and $s(Y)$ is the sample standard deviation (SD) of $Y_{i}$.

\section{Descriptive Statistics of the Return Series}

Table 1 summarizes the descriptive statistics of the returns' data. Specifically, authors report information on the minimum and maximum values and the three moments of the returns. From the Jarque-Bera (JB normality) test and the Ljung-Box (LB correlation test) for 20 lags, all the observed returns are neither normally distributed nor serially correlated. Negative values for the skewness indicate that all the returns' distributions are left skewed. The kurtosis value of all the returns is significantly greater than that of a normal distribution which is 3 . Furthermore, the kurtosis and studentized range statistics (which is the return range divided by the standard deviation) show that all the returns exhibit heavytailed behavior compared to the normal distribution. So, the skewness, kurtosis, and studentized range suggest that the observed returns' series should be analyzed under the skewness and heavy-tailedness assumptions. In our model, therefore, authors fit the generalized Student's $t$-distribution accommodating flexible skewness and heavy-tailedness to the returns' error distribution.

\section{Testing of Stationarity}

To assess whether the exchange rate and its returns' series have a unit root or are stationary, authors applied the Augmented Dickey-Fuller (ADF) test from Dickey and Fuller (1979). The results are reported in Table 2. Authors can see from the table, at all the 
Gadjah Mada International Journal of Business - May-August, Vol. 20, No. 2, 2018

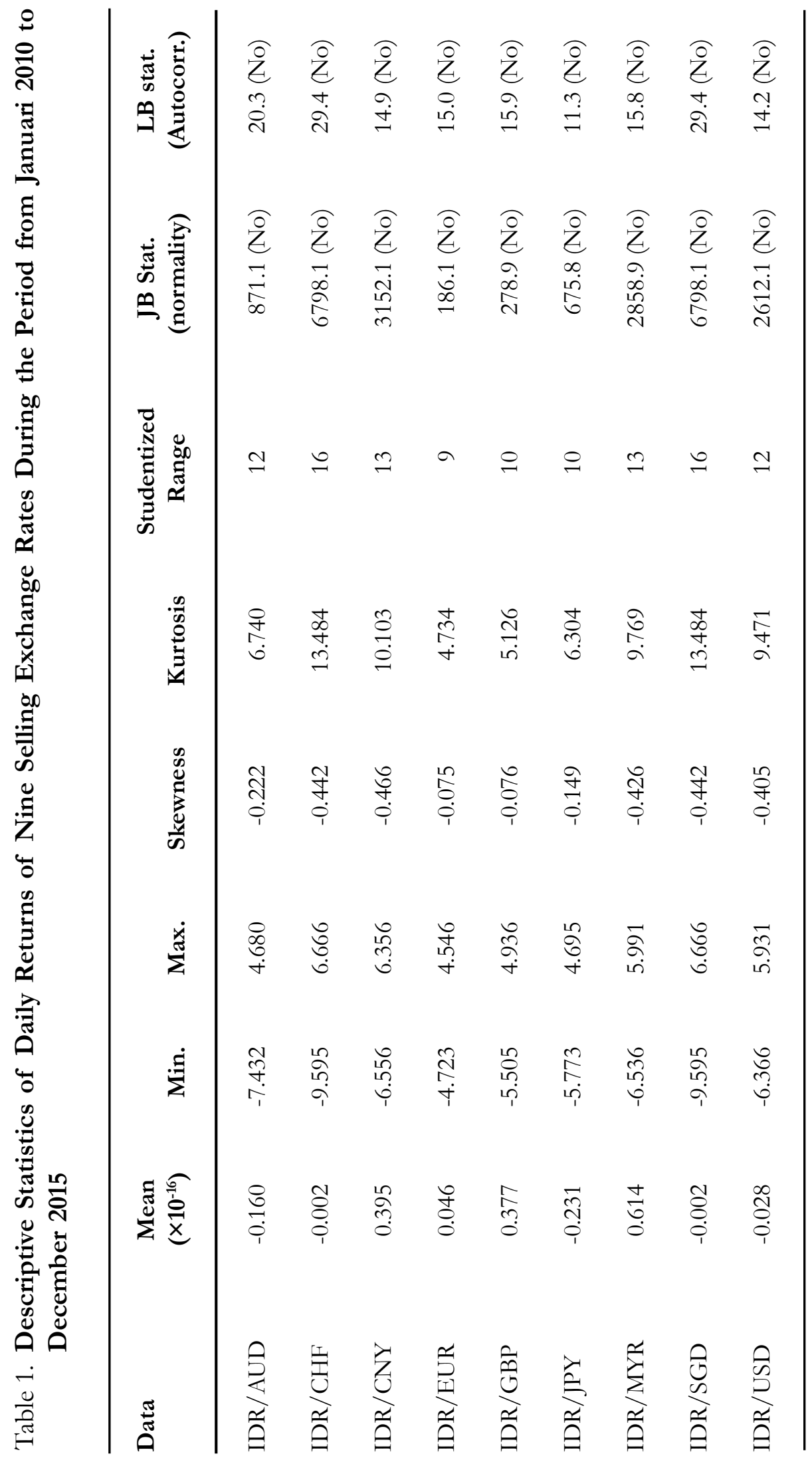


Nugrobo et al.

Table 2. The Output of ADF Unit Root Test for the Exchange Rates and Their Returns Series

\begin{tabular}{lccccccccc}
\hline $\begin{array}{l}\text { ADF } \\
\text { Stats. }\end{array}$ & AUD & CHF & CNY & EUR & GBP & JPY & MYR & SGD & USD \\
& & & & & & & & & \\
Rates & -1.90 & -0.84 & 0.19 & -0.87 & -0.13 & -2.50 & -1.47 & -0.45 & 0.87 \\
Returns & -39.62 & -37.53 & -38.96 & -36.58 & -38.49 & -39.21 & -37.96 & -36.45 & -38.76 \\
\hline
\end{tabular}

conventional levels of significance, the results indicate that the ADF test fails to reject the null hypothesis of a unit root for all rates' series, but allows for the rejection of the null hypothesis for all the returns' series. Therefore, authors conclude that all the returns might be considered as stationary series.

\section{Model Specification and Estimation Method}

In order to achieve the objectives, authors developed the volatility model so it has the following important statistical properties of a financial time series (Cont 2007; Tsay 2010; Degiannakis and Floros 2015; Sekerke 2015):

- Correlation between an asset's return and its changes of volatility. The negative correlation between asset's returns and volatility is usually called an asymmetric or leverage effect phenomenon. This means that volatility reacts differently to a large returns' increase or decrease, i.e. negative returns increase volatility, whereas any positive in the returns causes a decrease in volatility. Meanwhile, the positive correlation, usually called the symmetric effect, means that positive and negative returns have the same impact on future volatility.
- The unconditional distribution of financial returns often exhibits skewness (asymmetry) or heavy-tails (positive excess kurtosis) instead of symmetry and light tails implied by normal distribution.

- Volatility clustering, i.e. high-volatility events can be seen in certain time periods, whereas low-volatility events occur in other periods. The concept of volatility clustering is raised by the phenomenon of volatility persistence. In the SV context, it is indicated by positive autocorrelation in the volatility. Volatility persistence therefore indicates that future volatility will be influenced by today's volatility. When the persistence of the volatility is very high (close to 1 ), the volatility shocks do not decay (i.e. there is a reversion to the mean) quickly. Specifically, in the currency market, if volatility is persistent then the market is not efficient since the assimilation takes a long time (Laopodis 2005). Hence the volatility's persistence can be used to identify the choice of anchor currency.

Therefore, authors consider two specifications of the SV model where the errors of the return process have non-normal distribution and the model can capture the asymmetric behavior between returns and volatility. This is a class of the SV model with asymmetric effect and generalized Student- $t$ distributions as described below. 
In the equity markets, asset returns are known to have a correlation with their logarithms of conditional squared-volatilities. In order to capture the correlation, an Asymmetric Stochastic Volatility (ASV) model is often implemented. Authors therefore focus on the ASV model which is defined by

$$
\left.\begin{array}{l}
R_{t}=\exp \left(\frac{1}{2} h_{t}\right) \epsilon_{t} \\
h_{t+1}=\alpha+\phi\left(h_{t}-\alpha\right)+\sigma_{h} v_{t+1} \\
h_{1}=\mathcal{N}\left(0, \frac{\sigma_{h}^{2}}{1-\phi^{2}}\right) \\
\operatorname{corr}\left(\epsilon_{t}, v_{t+1}\right)=\rho
\end{array}\right\}
$$

where $\epsilon_{t}, v_{t+1} \sim \mathcal{N}(0,1)$ with $\mathcal{N}$ represents the normal distribution. The model assumes that the returns have no autocorrelation and allows for possible correlation between the return and volatility errors, which is indicated by $\rho$. In the above model, $h_{t}$ is the log return's variance, $\alpha$ is the stationary mean of the log return's variance, $\phi$ measures the degree of persistence of the log return's variance, and $\sigma_{b}$ is the standard deviation of the log return's variance. In this case, the log return's variance is assumed to follow a stationary $\mathrm{AR}(1)$ process with persistence parameter $0<\phi<1$. Using the same approach as in Nugroho and Morimoto (2014, 2015, 2016), Model (1) can be rewritten in the following form:

$$
\left.\begin{array}{l}
R_{t}=\exp \left(\frac{1}{2} h_{t}\right) \epsilon_{t} \\
h_{t+1}=\alpha+\phi\left(h_{t}-\alpha\right)+\varphi R_{t} \exp \left(-\frac{1}{2} h_{t}\right)+\psi \eta_{t+1} \\
h_{1}=\mathcal{N}\left(0, \frac{\psi^{2}}{1-\phi^{2}}\right) \\
\operatorname{corr}\left(\epsilon_{t}, \eta_{t+1}\right)=0
\end{array}\right\}
$$

where $\varphi=\rho \sigma_{b}, \psi^{2}=\left(1-\rho^{2}\right) \sigma_{b}^{2}$, and

$$
\eta_{t+1} \sim \mathcal{N}(0,1) \text {. }
$$

In particular, a negative correlation between $\epsilon_{t}$ and $v_{(t+1)}(\rho<0)$ induces an asymmet- ric (leverage) effect. This effect implies asymmetry, as a negative return, increases the conditional volatility, while a positive return decreases the conditional volatility. In contrast to the results from the equity markets, several empirical studies have found that foreign exchange returns usually exhibit symmetric effect $(\rho>0)$, implying that past positive and negative returns have the same effects on today's volatility.

The ASV model is then extended to accommodate the flexible heavy-tailedness and skewness in the conditional distribution of the returns. In particular, authors assume that the error of the return time series has either the Non-Central Student- $t$ (NCT) distribution or the generalized hyperbolic Skew Student- $t$ (SKT) distribution (see Nugroho and Morimoto (2014) for the explanation). Both distributions are not nested but the distributions include the normal and Student- $t$ distributions. Following Nugroho and Morimoto (2014, 2016), the ASV model with NCT-errors distribution, called the ASV-NCT model, has the following form for the return:

$$
\begin{array}{r}
R_{t}=\exp \left(\frac{1}{2} h_{t}\right) \sqrt{z_{t}}\left(\mu+\xi_{t}\right), z_{t} \sim \\
\mathcal{J G}\left(\frac{1}{2} v, \frac{1}{2} v\right), \xi_{t} \sim \mathcal{N}(0,1)
\end{array}
$$

where $\mu$ is the noncentrality parameter and $\mathcal{I G}$ represents inverse gamma distribution. Meanwhile, the ASV model with SKT-errors distribution called the ASV-SKT model has the following form for the return:

$$
R_{t}=\exp \left(\frac{1}{2} h_{t}\right)\left[\beta\left(z_{t}-\frac{v}{v-2}\right)+\sqrt{z_{t}} \xi_{t}\right]
$$

In this case, the parameters $\beta$ and $\nu$, respectively, express the measure of skewness and degrees of freedom. When $\mu, \beta=0$, the above models reduce to the ASV model with the Student- $t$ distribution (hereafter, ASV-T model). 
Parameters $\mu$ and $\beta$ provide the measure of the degree of misspecification of a hypothesized model.

The challenge when estimating the SV model stems from the fact that the likelihood function of the model is expressed by a high dimensional integral which does not have a closed-form solution due to the presence of a latent volatility process. Hence various likelihood-based methods have been proposed to analyse the SV models. In this study, authors employ a full likelihood-based method for the models' estimations and inferences, using the Bayesian MCMC.

The model parameters that authors have to estimate are $\theta=(\alpha, \phi, \varphi, \psi, \mu, \beta, v)$, and latent $\log$-volatility $h$, for $t=1,2, \ldots$. Here, authors perform the Bayesian approach for parameter estimations by the MCMC algorithm. As is well known, the Bayesian approach provides the following advantages (Lee and Song 2008):

(a) The precision of the parameter estimates can be obtained with good prior information.

(b) As the sampling-based Bayesian methods do not rely on the asymptotic theory, it gives reliable statistical inferences even with small sample sizes.

(c) It has similar optimal asymptotic properties as the maximum likelihood approach.

The Bayesian MCMC algorithm is implemented in two steps (Tan 2008). The first step is to simulate a Markov chain for each unknown parameter converging to its conditional posterior density after a sufficient number of draws/iterations. In each iteration, the Markov chain for each parameter is updated by using the current value drawn for each of the other parameters. In particular, this study applies the RMHMC method, developed by Nugroho and Morimoto (2014, 2015, 2016), to produce
Markov chains for the parameter that cannot be drawn directly. The second step is to employ a Monte Carlo integration to compute the posterior mean and the standard deviation of the parameters on the basis of the draws after the burn-in period.

Let $\mathrm{R}=\left(\mathrm{R}_{1}, \mathrm{R}_{2}, \ldots, \mathrm{R}_{\mathrm{T}}\right), \mathrm{h}=\left(h_{1}, h_{2}, \ldots, h_{\mathrm{T}}\right)$, and $z=\left(z_{1}, z_{2}, \ldots, z_{T}\right)$ be the vectors of observations, log-volatility, and latent variables, respectively, $f(\mathrm{R} \mid \cdot)$ denotes the likelihood function, $p(\mathrm{~h} \mid \cdot)$ denotes the conditional density function of the log-volatility, $p(z \mid v)$ denotes the density of $\mathrm{z}$ conditional on $v$, and $p(\theta)$ denotes the prior density of the para-meters. With these notations and applying Bayes's theorem, the posterior density over the parameters, log-volatility, and latent variables are equal to the likelihood of observing the data given a certain parameter setting multiplied by the density functions, which is expressed by

$p(\theta, \mathrm{h}, \mathrm{z} \mid \mathrm{R})=f(\mathrm{R} \mid \cdot) \times p(\mathrm{z} \mid v) \times p(\mathrm{~h} \mid \cdot) \times p(\theta)$.

This study assumes the following prior densities for the parameters of interest: Normal distribution for $\alpha, \varphi, \mu, \beta$, beta distribution for $\theta$, inverse gamma distribution for $\psi^{2}$, and gamma distribution for $v$. Drawing each parameter (including log-volatility and latent variables) from the joint posterior density of the parameters is similar to the approach of Nugroho and Morimoto (2014).

In summary, the drawing procedure is as follows:

1. Initialize $\theta, b, z$.

2. Draw $\alpha, \varphi, \psi^{2}, \mu, \beta$ directly from each posterior density.

3. Draw $\phi$ from its posterior density using the RMHMC algorithm.

4. Draw $v$ from its posterior density using the RMHMC algorithm.

5. Draw $z$ from its posterior density using the RMHMC algorithm. 
6. Draw h from its posterior density using the RMHMC algorithm.

This study constructs the Markov chain for each parameter by considering a chain of size $N=15,000$ and a burn-in period of $N_{0}=$ 5,000 . This burn-in is employed to reduce the risk of inferential bias caused by the effects of the starting values (Andersson et al. 2000). The remaining draws of $N-N_{0}=10,000$ are then collected from the chain of each parameter as the posterior sample, and to carry out all the parameter inference such as the posterior mean, standard deviation, credible interval, and efficiency sampler.

\section{Model Selection Criterion}

In order to compare all the competing models, authors consider information criteria on the basis of the likelihood ratio model choice's criterion, such as the Bayes factor. This well-know model comparison statistic is associated with the Bayesian approach and introduced by Kass and Raftery (1995). This criterion is very general and do not require nested alternative models. For the investigation and comprehensive review of the Bayes factor consistency property, see Moreno et al. (2010) and Wang and Maruyama (2016).

The Bayes factor is simply the ratio of the marginal likelihood (marginal density) of one model to the marginal likelihood of a competing model. Let $M_{0}$ and $M_{1}$ be the null and given models, respectively, and $m(\mathrm{D} \mid M k)$ denotes the marginal likelihood of the observed data $D$ with a sample size $n$ under one of the competing models $M_{k} k=0,1$. The Bayes factor of the model $\mathrm{M}_{1}$ with respect to the model $M_{0}$ is given by

$$
\mathrm{BF}_{10}=\frac{m\left(\mathrm{D} \mid M_{1}\right)}{m\left(\mathrm{D} \mid M_{0}\right)}
$$

The Bayes factor is thus a summary of the evidence provided by the data in favor of a statistically given model $M_{1}$ as opposed to the null model $M_{0}$, i.e., in principle it measures how well the given model $M_{1}$ is supported by the data relative to the null model $M_{0}$.

On the basis of the similarity to the likelihood ratio criterion, the rules to determine the evidence strength associated with the value of $\ln \left(\mathrm{BF}_{10}\right)$ were proposed by Kass and Raftery (1995). Specifically, they indicated that a nega-tive $\ln \left(\mathrm{BF}_{10}\right)$ is taken as support for $M_{0}$, a value between 0 and 1 does not allow any conclu-sion to be drawn, a value between 1 and 3 in-terprets "positive" support in favor of select-ing $M_{1}$, a value between 3 and 5 is considered "strong" support for $M_{1}$, and a value in excess of 5 is considered "very strong" support for $M_{1}$.

Since the marginal likelihood cannot usu-ally be written in closed form, various numeri-cal approximation methods have been pro-posed to estimate the marginal likelihood from the MCMC output. In this study, authors fo-cus on the estimator proposed by Gelfand and Dey (1994) which is simpler, faster, and more general.

\section{Results}

This section analyzes the daily meancorrected and variance-scaled returns of nine foreign exchange rate traded by Bank Indonesia. The exchange rate used is the bank's selling rate. All empirical results are obtained via the code implementation of MATLAB for the MCMC-simulation.

As reported in the data description section, when the returns were examined for skewness and kurtosis, the tests provided evidence of significant skewness and heavy- 
tailedness for the returns distribution. To model these features and also the asymmetric effect, authors proceed by applying the ASV models discussed in the previous section. Here, the statistical significance of the parameter estimates in the models is indicated by the Highest Posterior Density (HPD) interval proposed by Chen and Shao (1999).

\section{Model Selection}

First, authors compare four competitive ASV models. To assess the goodness of the estimated models, authors calculate the marginal likelihood from the MCMC output by using the Gelfand and Dey (GD) method. The results are shown in Table 3 . The marginal likelihoods are required for the calculation of the
Bayes factor for comparing any two nonnested models. As explained in the previous section, the Bayes factor is defined as the ratio of the marginal likelihood values of two competing models. According to the suggestion given by Kass and Raftery (1995) in terms of the $\log$ Bayes factor (i.e., the difference of the log marginal likelihoods) criterion, this study found that the log Bayes factors provide very strong evidence in support of the SKT distribution rather than the other distribution in all cases. It indicates that the ASVSKT model is the best model among all the considered models for all the data series. Authors do note that the ASV-T and ASV-NCT models are very competitive and outperform the ASV model with normal error distribution. Although not reported, authors find that

Table 3. Log Marginal Likelihood Estimates for All Competing ASV Models

\begin{tabular}{lcccc}
\hline \multirow{2}{*}{ Data } & \multicolumn{3}{c}{ Model } \\
\cline { 2 - 5 } & ASV & ASV-T & ASV-NCT & ASV-SKT \\
\cline { 2 - 4 } IDR/AUD & $-1940.2^{(4)}$ & $-1920.5^{(3)}$ & $-1919.4^{(2)}$ & $-1898.5^{(1)}$ \\
IDR/CHF & $-1695.5^{(4)}$ & $-1649.8^{(2)}$ & $-1660.4^{(3)}$ & $-1637.8^{(1)}$ \\
IDR/CNY & $-1476.9^{(4)}$ & $-1459.6^{(2)}$ & $-1463.6^{(3)}$ & $-1442.0^{(1)}$ \\
IDR/EUR & $-2010.0^{(4)}$ & $-1994.6^{(2)}$ & $-2004.4^{(3)}$ & $-1966.9^{(1)}$ \\
IDR/GBP & $-1996.8^{(4)}$ & $-1981.4^{(2)}$ & $-1986.8^{(3)}$ & $-1962.2^{(1)}$ \\
IDR/JPY & $-1896.6^{(4)}$ & $-1897.2^{(3)}$ & $-1884.2^{(2)}$ & $-1858.1^{(1)}$ \\
IDR/MYR & $-1807.9^{(4)}$ & $-1792.8^{(2)}$ & $-1799.9^{(3)}$ & $-1772.9^{(1)}$ \\
IDR/SGD & $-1761.7^{(4)}$ & $-1736.9^{(2)}$ & $-1751.7^{(3)}$ & $-1720.9^{(1)}$ \\
IDR/USD & $-1472.5^{(4)}$ & $-1463.8^{(3)}$ & $-1462.6^{(2)}$ & $-1438.5^{(1)}$ \\
\hline
\end{tabular}

Note: The figures in the parentheses denote the relative rank of a model's GD, where the model with the smallest marginal likelihood ranks first. 
the 95 percent HPD interval of $\mu$ (noncentrality parameter) in the ASV-NCT model includes 0 for all the considered return data. In fact, the posterior distribution of $\mu$ is approximately symmetrical about zero, suggesting that the all return data demonstrate insufficient departure from the non-centrality assumption for the returns' distribution.

Let us now concentrate on the estimation of the ASV-SKT model. Because of space constraints, this study reports only the parameter estimates of the ASV-SKT model which provided the best fit among all the competing models for the exchange rates having an asymmetric effect. The estimation results for the key parameters, including the posterior means, standard deviations, 95 percent HPD intervals, and Inefficiency Factors (IF) are reported in Table 4.

\section{Presence of the Return-Volatility Correlation}

Authors investigate whether the volatility displays symmetric or asymmetric responses to the observed return series. This information is typically specified by parameter $\rho$ which denotes the direct correlation between the errors in both returns and volatility. Authors found that the posterior mean of $\rho$ is negative for the IDR/AUD, IDR/GBP, IDR/ MYR, and IDR/SGD series and positive for the other series. In all competing models (not reported), save the IDR/CNY, IDR/EUR, IDR/GBP, and IDR/MYR returns, authors found that the estimator of $\rho$ is significantly different from zero in terms of the 90 percent HPD interval, indicating that the relationship between returns and conditional volatility cannot be rejected. In fact, it was found

Table 4. Summary of the Posterior Sample of Key Parameters in the ASV-SKT Model Fits to the Five Returns Series Which Have Significant Correlation between Returns and Volatility

\begin{tabular}{ccccccc}
\hline Par. & Stats. & IDR/AUD & IDR/CHF & IDR/JPY & IDR/SGD & IDR/USD \\
\hline \multirow{4}{*}{$\phi$} & Mean & 0.958 & 0.948 & 0.933 & 0.943 & 0.947 \\
& SD & 0.014 & 0.016 & 0.021 & 0.016 & 0.013 \\
& LB & 0.930 & 0.916 & 0.890 & 0.912 & 0.919 \\
& UB & 0.984 & 0.977 & 0.972 & 0.973 & 0.970 \\
& IF & 133.8 & 84.1 & 184.4 & 106.6 & 107.0 \\
& Mean & -0.409 & 0.282 & 0.180 & -0.155 & 0.140 \\
& SD & 0.101 & 0.118 & 0.102 & 0.089 & 0.072 \\
& LB & -0.582 & 0.084 & 0.018 & -0.229 & 0.024 \\
& UB & -0.248 & 0.471 & 0.346 & -0.006 & 0.260 \\
& IF & 109.8 & 58.4 & 32.0 & 17.4 & 19.9 \\
& Mean & 21.1 & 8.8 & 17.4 & 18.5 & 15.2 \\
& SD & 4.4 & 1.8 & 4.44 & 4.0 & 4.4 \\
& UB & 14.4 & 5.9 & 9.9 & 12.6 & 8.7 \\
& & & & & & \\
\hline
\end{tabular}


Table 4. Continued

\begin{tabular}{ccccccc}
\hline Par. & Stats. & IDR/AUD & IDR/CHF & IDR/JPY & IDR/SGD & IDR/USD \\
\hline \multirow{6}{*}{$*$} & LB & 28.3 & 11.4 & 24.1 & 25.4 & 21.7 \\
& IF & 124.8 & 175.5 & 173.1 & 148.6 & 153.8 \\
& Mean & -0.277 & -0.018 & -0.479 & -0.167 & -0.117 \\
& SD & 0.264 & 0.087 & 0.266 & 0.229 & 0.222 \\
& UB & -0.693 & -0.162 & -0.893 & 0.197 & -0.479 \\
& LB & 0.163 & 0.118 & -0.074 & -0.556 & 0.222 \\
& IF & 65.2 & 23.3 & 70.1 & 33.0 & 49.6 \\
\hline
\end{tabular}

that the leverage effect appears in the IDR/ AUD and IDR/SGD returns. This result suggests that a present negative return (i.e., bad news) on those assets will increase the future volatility. Using similar arguments the future volatility decreases when a positive return (i.e., good news) arrives today. For the IDR/CHF, IDR/JPY, and IDR/USD returns, the estimated $\rho$ parameter is positive. This result implies that today's news has the same effect on the future volatility. However, bad news has greater effect on the volatility compared to the good news (Ho et al. 2017). If the fact reveals this comparison, then the risk premium will increase. As a consequence, there will be frequent speculation on the Indonesian foreign exchange market. Speculation might be good, but it could be a driving force to a financial crisis if it is not well managed (Corsetti et al. 1999).

\section{Distribution of Asset Returns}

In the ASV-SKT model, the extent of the leptokurtosis in the data is measured by the degrees of freedom parameter, $v$. One can also interpret this as a magnitude of the heavytaildness. Authors found that the posterior mean of $v$ ranges from 8.8 for IDR/CHF to
21.1 for IDR/AUD, which indicates a heavytailedness in the exchange rate returns' distributions.

Regarding the skewness parameter, $\beta$, in the ASV-SKT model, authors found that the posterior mean ranges from -0.480 for IDR/ JPY to -0.018 for IDR/CHF. For all exchange rates' data, the 90 percent HPD interval includes zero, meaning the negativity of $\beta$ is not credible. However, their posterior distributions are primarily located in the negative range as shown in Figure 3. This supports the evidence of skewness in all the exchange rates's data and makes a consistent finding that the ASVSKT model is superior to all the other competing models.

\section{Applying Volatility Persistence to Validate the Anchor Currency}

We then observed the persistence parameter's estimated value for volatility, $\phi$. The persistence in volatility is used to investigate the half-life of the volatility. This is defined as the average number of time periods for the volatility to move halfway back towards its unconditional mean. The persistence and half-life, measured by $-\ln (2) / \ln (\phi)$ (see van der 
Figure 3. Histograms of the Posterior Distribution of Parameter $\beta$ in the ASV-SKT Model Adopting all the Returns Series
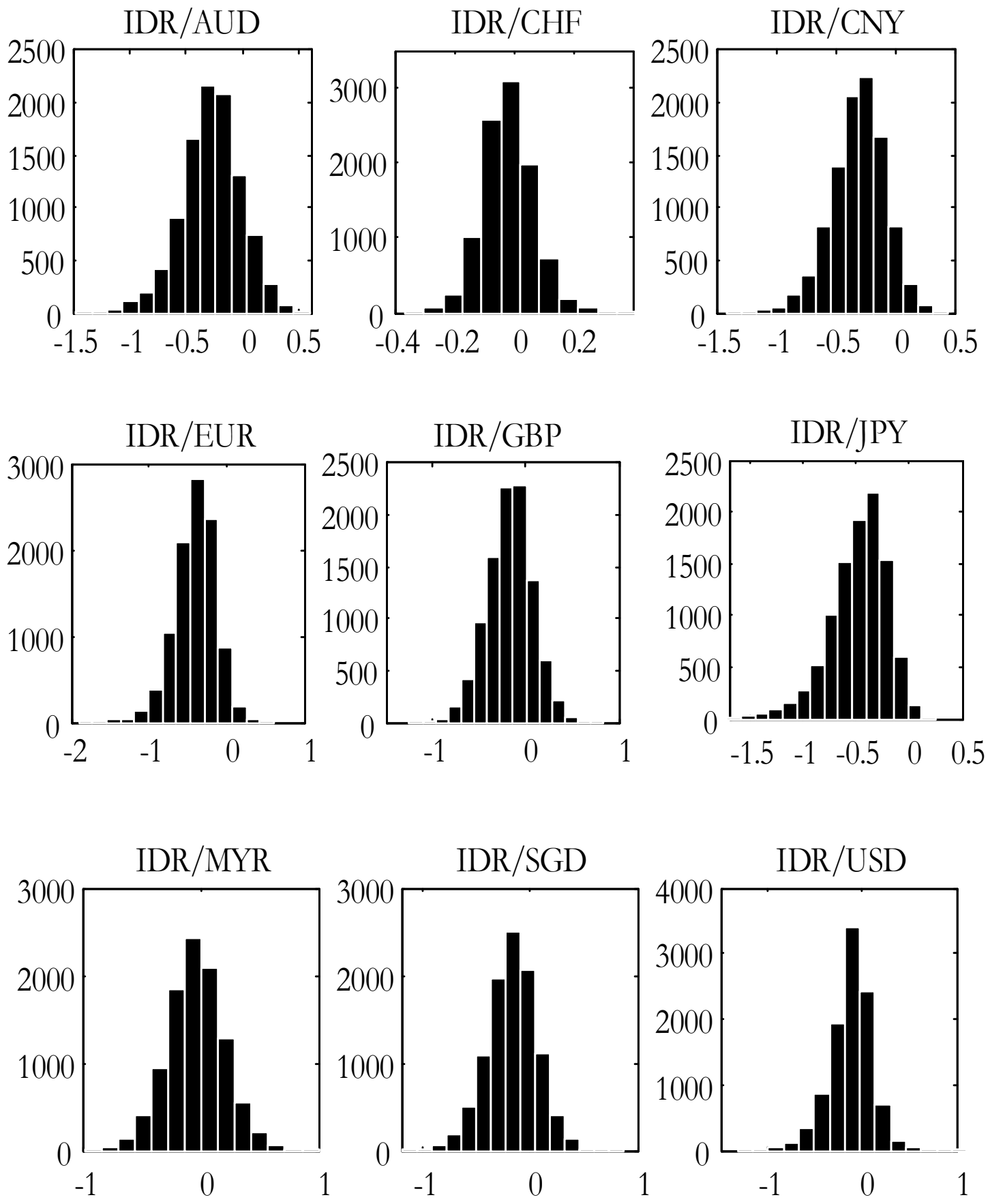
Ploeg 2006), of the volatility of the returns series are reported in Table 5.

We found that all the considered series exhibited high persistence in all models, typically ranging from 0.88 to 0.96 . In terms of the mean reversion, the half-life of volatility shocks is about 6 to 17 days. The highest level of persistence was exhibited by the IDR/MYR with a half-life about 13 to 17 days, while the least persistence level was recorded in the IDR/GBP with a half-life about 8 to 10 days. In particular, the IDR/MYR, IDR/CNY, and IDR/AUD series have weaker mean reversion than the hard currencies. In other words, volatility for the hard currencies appears to be less persistent. This empirical evidence is similar to the finding in Los (2003), i.e. the anchor currency markets are predominantly antipersistent. This means that the volatility of the hard currencies has a short period of time to get back to average which implies in- vestors will prefer hard currencies. On the other hand, the three former currencies (AUD, CNY, MYR) belong to Small Open Economies (SOE) which are potentially affected by the monetary policies of the hard currencies's countries. Therefore, anchoring the IDR to the established hard currencies (EUR, GBP, JPY, and USD) is more appropriate than anchoring it to other currencies.

Authors now turn to the information about the conditional volatility, as reflected in the variance (squared volatility) series, $\exp (b)$. The estimates of the variance for all the returns series under the ASV-SKT model are displayed in Figure 4. It can be seen that the figure shows that the IDR/CNY and IDR/ USD variances have similar pattern. These variances had the highest value on September $23^{\text {rd }}, 2011$ (Friday) corresponding to the positive return on September 22 2011 (Thursday). Again, a similar pattern of variances is

Table 5. Persistence and Half-Life (days) Volatility Measure of the Returns Series

\begin{tabular}{lcccccccc}
\hline & \multicolumn{2}{c}{ ASV } & \multicolumn{2}{c}{ ASV-T } & \multicolumn{2}{c}{ ASV-NCT } & \multicolumn{2}{c}{ ASV-SKT } \\
\cline { 2 - 9 } Data & $\phi$ & $\begin{array}{c}\text { Half- } \\
\text { Life }\end{array}$ & $\boldsymbol{\phi}$ & $\begin{array}{c}\text { Half- } \\
\text { Life }\end{array}$ & $\boldsymbol{\phi}$ & $\begin{array}{c}\text { Half- } \\
\text { Life }\end{array}$ & $\boldsymbol{\phi}$ & $\begin{array}{c}\text { Half- } \\
\text { Life }\end{array}$ \\
\hline IDR/AUD & 0.947 & 13 & 0.952 & 15 & 0.950 & 14 & 0.958 & 17 \\
IDR/CHF & 0.882 & 6 & 0.945 & 13 & 0.945 & 13 & 0.948 & 13 \\
IDR/CNY & 0.938 & 11 & 0.957 & 16 & 0.957 & 16 & 0.956 & 16 \\
IDR/EUR & 0.918 & 9 & 0.927 & 10 & 0.931 & 10 & 0.923 & 9 \\
IDR/GBP & 0.911 & 8 & 0.917 & 8 & 0.924 & 9 & 0.928 & 10 \\
IDR/JPY & 0.909 & 8 & 0.930 & 10 & 0.931 & 10 & 0.933 & 10 \\
IDR/MYR & 0.948 & 13 & 0.960 & 17 & 0.959 & 17 & 0.959 & 17 \\
IDR/SGD & 0.931 & 10 & 0.945 & 13 & 0.947 & 13 & 0.944 & 13 \\
IDR/USD & 0.934 & 11 & 0.948 & 13 & 0.951 & 14 & 0.947 & 13 \\
\hline
\end{tabular}


also found in the IDR/AUD, IDR/GBP, IDR/MYR, and IDR/SGD series. In this case, the highest variance occurred on September 26th, 2011 (Monday) corresponding to the lowest negative return on September 23 ${ }^{\text {rd }}, 2011$ (Friday). Meanwhile, the highest variances for the IDR/CHF, IDR/EUR, and IDR/JPY series occurred on August 12 $2^{\text {th }}, 2011$ (Friday), May 21 ${ }^{\text {st }}, 2010$ (Friday), and May 10 $0^{\text {th }}, 2010$ (Monday). Those findings are consistent with previously reported results in terms of corre- lation between returns and volatility. In the IDR/CHF case, authors note that the extreme returns' values of the IDR/CHF series are clearly manifested by the associated variances values which jump up more under the SV normal than under the other models. Generally speaking, the average volatilities of $\exp (1 / 2 b$ ) vary from 0.7 to 0.91 , where the IDR/JPY and IDR/CHF returns series give the highest and lowest average volatilities, respectively.

Figure 4. Time Series Plots of the Variances from an ASV-SKT Model's Fit to All Returns Series
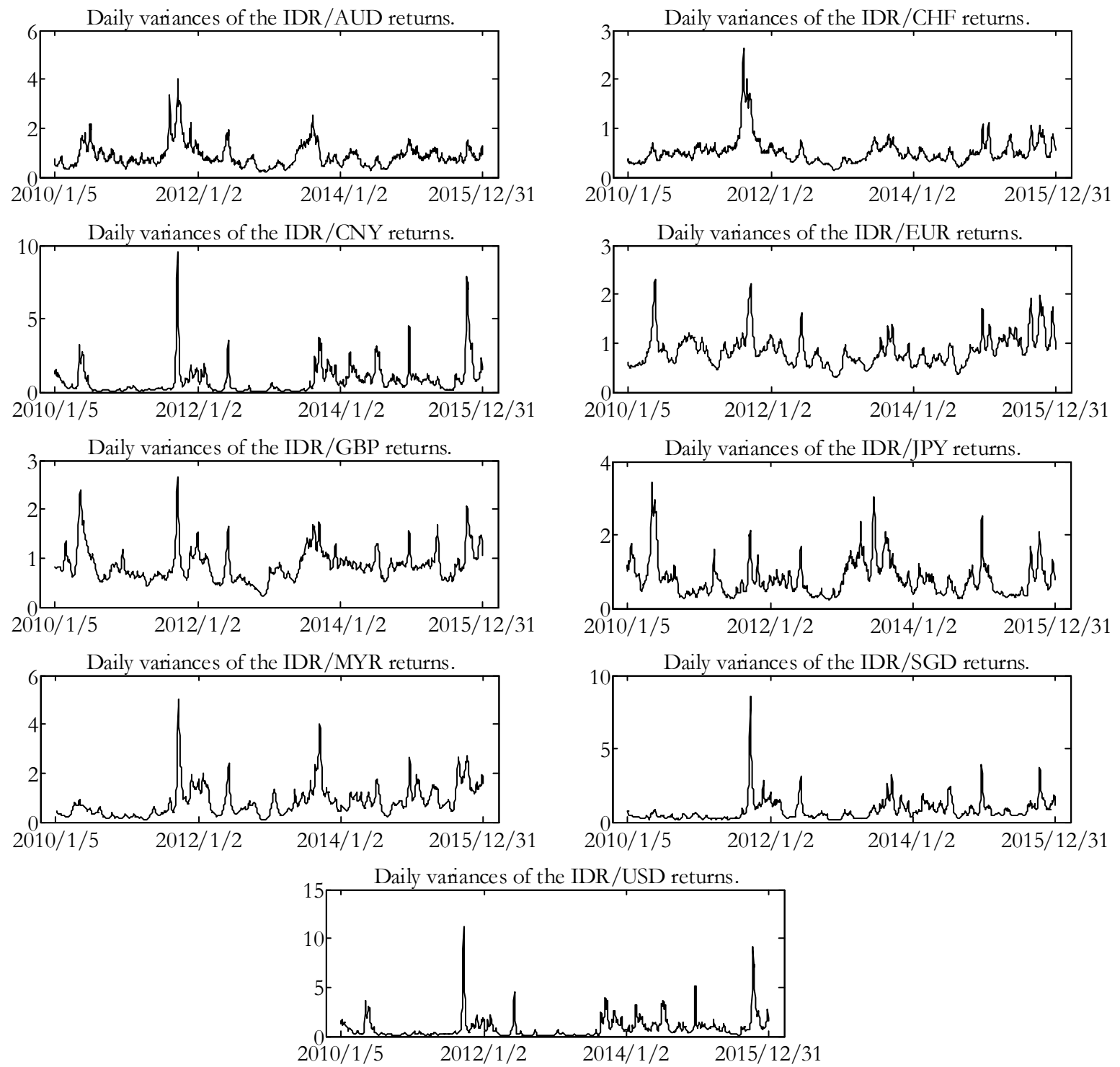


\section{Conclusions and Future Work}

This study investigated the ASV models to analyze the short-run behavior of volatility on Indonesia's foreign exchange market and to explain anchor currency's choice. Our models are the ASV models with generalized Student- $t$ distribution for the return errors, which capture the return-volatility correlation and the distribution accommodating the flexible skewness and heavy-tailedness.

In summary, our empirical results suggest a positive and significant relation between the IDR/CHF, IDR/JPY, and IDR/USD returns and their conditional varaince. For the IDR/AUD and IDR/SGD returns, the parameter estimates suggest a negative and significant corelation between the return and its conditional variance. On the basis of the Bayesian model's selection criterion, this study found that features such as skewness and heavy tails should be incorporated in the ASV model, since they provide significant improvements to the model's fit over the usual normal model. Considering the persistence and halflife of volatility, the empirical results showed that the hard currencies are less persistent and have stronger mean reversion than the SOE currencies. Therefore, the Goverment of Indonesia should confidently anchor the IDR to the established hard currencies eventhough there are emerging new hard currencies, i.e. the CNY and AUD.

Yu et al. (2006) introduced a closely related SV model by applying the Box-Cox transformation to the volatility equation. They found that exchange rate data provide some evidence against the lognormal specification. Extending the model and results derived in this study to apply the Box-Cox transformation to the volatility equation is on our agenda for future research.

\section{ACKNOWLEDGEMENTS}

We thank the seminar participants at the Asian Mathematical Conference (AMC) held on July 25th-29th, 2016 in Bali, Indonesia, for the questions, comments, and suggestions on our topic. Authors also received valuable comments from participants at the Call for Papers 2016 organized by FEB UKSW, on November 3rd, 2016.

\section{References}

Abdalla, S. Z. S. and P. Winker. 2012. Modelling stock market volatility Using univariate GARCH models: Evidence from Sudan and Egypt. International Journal of Economics and Finance 4 (8): 161-176.

Andersson, H., and T. Britton. 2000. Stochastic Epidemic Models and Their Statistical Analysis. New York: Springer-Verlag.

Black, F. 1976. Studies of stock market volatility changes. Proceedings of the 1976 Meetings of the Business and Economic Statistics. American Statistical Association: 177-181.

Bollerslev, T. 1986. Generalized autoregressive conditional heteroskedasticity. Journal of Econometrics 31 (3): $307-327$

Chen, M.-H., and Q-M. Shao. 1999. Monte carlo estimation of Bayesian credible and HPD intervals. Journal of Computational and Graphical Statistics 8 (1): 69. 
Cont, R. 2007. Volatility clustering in financial markets: Empirical facts and agent-based models. In G. Teyssière and A. P. Kirman (Eds.). Long Memory in Economics. Berlin: Springer, pp.289-309.

Conway, E. 2009. UN wants new global currency to replace dollar. [online] Available at: <https:// www.telegraph.co.uk/finance/currency/6152204/UN-wants-new-global-currency-to-replacedollar.html> [Accessed 24 Nov. 2017].

Corsetti, G., P. Pesenti, and N. Roubini. 1999. What caused the Asian currency and financial crisis? Japan and the World Economy 11 (3): 305-373.

Degiannakis, S. and C. Floros. 2015. Modelling and Forecasting High Frequency Financial data. London: Palgrave Macmillan UK.

Dickey, D. A., and W. A. Fuller. 1979. Distribution of the estimators for autoregressive time series with a unit root. Journal of the American Statistical Association 74 (366): 427.

Eichengreen, B. 2005. Sterling's Past, Dollar's Future: Historical Perspectives on Reserve Currency Competition. [online] Cambridge, MA. Available at: < http://www.nber.org/papers/w11336.pdf > .

Engle, R. F. 1982. Autoregressive conditional heteroscedasticity with estimates of the variance of United Kingdom inflation. Econometrica 50 (4): 987-1007.

Gelfand, A. E., and D. K. Dey. 1994. Bayesian model choice: Asymptotics and exact calculations. Journal of the Royal Statistical Society. Series B (Methodological), .

Goyal, A. 2017. Intervention and signaling: Interaction between central banks and FX markets in an emerging market. The Singapore Economic Review 62 (1): 193-225.

Harvey, A. C., and N. Shephard. 1996. Estimation of an asymmetric stochastic volatility model for asset returns. Journal of Business and Economic Statistics 14 (4): 429.

Ho, K.-Y., Y. Shi, and Z. Zhang. 2017. Does news matter in China's foreign exchange market? Chinese RMB volatility and public information arrivals. International Review of Economics and Finance 52: 302321.

IMF Website. 2016. IMF Adds Chinese Renminbi to Special Drawing Rights Basket. [online]. Available at: < http:/ /www.imf.org/en/News/Articles/2016/09/29/AM16-NA093016IMF-Adds-Chinese-Renminbito-Special-Drawing-Rights-Basket> [Accessed 15 Nov. 2017].

Kass, R. E., and A. E. Raftery. 1995. Bayes factors. Journal of the American Statistical Association. [online] 90(430), pp.773-795. Available at: <http://www.jstor.org/stable/2291091?origin=crossref $>$.

Kim, S. -J. 2015. Australian gollar carry trades: Time varying probabilities and determinants. International Review of Financial Analysis 40: 64-75.

Kompas. 2015. Importir Kena Dampak Rupiah (March) (14): 1.

Laopodis, N. T. 2005. Feedback trading and autocorrelation interactions in the foreign exchange market: Further evidence. Economic Modelling 22 (5): 811-827.

Lee, S.-Y., and X-Y. Song. 2008. Bayesian model comparison of structural equation models. Random Effect and Latent Variable Model Selection. New York: Springer Science and Business Media: 121-150.

Los, C. A. 2003. Financial Market Risk: Measurement and Analysis. London: Routledge.

Low, C. 2004. The fear and exuberance from implied volatility of SandP 100 index options. The Journal of Business 77 (3): 527-546.

Moon, W., 2007. A case for a coordinated basket for Asian countries. In A Basket Currency for Asia 124141. New York: Routledge 
Moreno, E., F. J. Girón, and G. Casella. 2010. Consistency of objective Bayes factors as the model dimension grows. Annals of Statistics 38 (4): 1937-1952.

Mukhlis, I., 2011. Analisis volatilitas nilai tukar mata uang rupiah terhadap dolar. Journal of Indonesian Applied Economics, 5(2), pp.178-182.

Nugroho, D.B. and Morimoto, T., 2014. Realized non-linear stochastic volatility models with asymmetric effects and generalized Student's t-distributions. Journal of the Japan Statistical Society, 44(1), pp.83118.

Nugroho, D.B. and Morimoto, T., 2015. Estimation of realized stochastic volatility models using Hamiltonian Monte Carlo-Based methods. Computational Statistics, 30(2), pp.491-516.

Nugroho, D.B. and Morimoto, T., 2016. Box-Cox realized asymmetric stochastic volatility models with generalized Student's t -error distributions. Journal of Applied Statistics, 43(10), pp.1906-1927.

Nugroho, D.B. and Susanto, B., 2017. Volatility modeling for IDR exchange rate through APARCH model with student- $t$ distribution. In: AIP Conference Proceedings. AIP Publishing LLC, p.40005.

Nugroho, D.B., Susanto, B. and Pratama, S.R., 2017. Estimation of exchange rate volatility using APARCHtype models: A case study of Indonesia (2010-2015). Jurnal Ekonomi dan Ekonomi Studi Pembangunan, 9(1), pp.65-75.

Ogawa, E. and Shimizu, J., 2009. Currency denomination in Asian Bond Markets. In: K. Hamada, B. Reszat and U. Volz, eds., Towards monetary and financial integration in East Asia. Cheltenham: Edward Elgar Publishing Limited.

Poon, S.-H., 2005. A practical guide to forecasting financial market volatility. Chichester: John Wiley and Sons.

Saadah, S. and Panjaitan, Y., 2016. The green shoe option's effectiveness at stabilizing the IPO's stock price on the Indonesian Stock Exchange (2000-2013). Gadjah Mada International Journal of Business, 18(1), p.71.

Salim, F.C., Nugroho, D.B. and Susanto, B., 2016. Model volatilitas GARCH(1,1) dengan error Student-t untuk kurs beli EUR dan JPY terhadap IDR. Jurnal MIPA, 39(1), pp.63-69.

Salvatore, D., 2013. International economics. 11th ed. New York: John Wiley and Sons.

Saputri, E.D., Nugroho, D.B. and Setiawan, A., 2016. Model volatilitas ARCH(1) dengan return error berdistribusi skewed Student-t. Jurnal MIPA, 39(1), pp.78-84.

Sekerke, M., 2015. Bayesian risk management: A guide to model risk and sequential learning in financial markets. New York: John Wiley and Sons.

Sumiyana, S., 2007. Behavior of stock price variability over trading and nontrading periods, and daily return volatility. Gadjah Mada International Journal of Business, 9(3), pp.409-453.

Tan, Z., 2008. Monte Carlo integration with Markov chain. Journal of Statistical Planning and Inference 138 (7): 1967-1980.

Taylor, S. J. 1982. Financial returns modelled by the product of two stochastic processes - A study of the daily sugar prices 1961-75. In N. Shephard (Ed.), Stochastic volatility: Selected readings: 60-82. Oxford University Press.

Taylor, S. J. 1994. Modeling stochastic volatility: A review and comparative study. Mathematical Finance 4 (2): 183-204. 
Triady, M. S., R. Kurniasari, A. F. Utami, and M. I. Sofyan. 2016. Investigation of leverage effect in Indonesian Stock Market. International Journal of Economics and Management 10 (S1): 1-17.

Tsay, R. S. 2010. Analysis of Financial Time Series ( $3^{\text {rd }}$ ed.). New York: John Wiley and Sons.

Tsiotas, G. 2012. On generalised asymmetric stochastic volatility models. Computational Statistics and Data Analysis 56 (1): 151-172.

van der Ploeg, A. P. C. 2006. Stochastic Volatility and the Pricing of Financial Derivatives. Amsterdam: Rozenberg Publishers.

Wang, M., and Y. Maruyama. 2016. Consistency of Bayes factor for nonnested model selection when the model dimension grows. Bernoulli [online] 22 (4): 2080-2100. Available at: < http://projecteuclid.org/ euclid.bj/1462297675>.

XE Website. 2017. IDR - Indonesian Rupiah. [online]. Available at: <http://www.xe.com/currency/idrindonesian-rupiah> [Accessed 6 Nov. 2017].

Yu, J., Z. Yang, and X. Zhang. 2006. A class of nonlinear stochastic volatility models and its implications for pricing currency options. Computational Statistics and Data Analysis 51 (4): 2218-2231. 